\title{
Bicultural landscapes and ecological restoration in the compact city: The case of Zealandia as a sustainable ecosanctuary
}

Bruno Marques, Jacqueline McIntosh, William Hatton \& Danielle Shanahan

To cite this article: Bruno Marques, Jacqueline McIntosh, William Hatton \& Danielle Shanahan (2019) Bicultural landscapes and ecological restoration in the compact city: The case of Zealandia as a sustainable ecosanctuary, Journal of Landscape Architecture, 14:1, 44-53, DOI: 10.1080/18626033.2019.1623545

To link to this article: https://doi.org/10.1080/18626033.2019.1623545

\section{Published online: 05 Jun 2019.}

Submit your article to this journal $\square$

View Crossmark data ऍ 


\title{
Bicultural landscapes and ecological restoration in the compact city: The case of Zealandia as a sustainable ecosanctuary
}

\author{
Bruno Marques, Jacqueline McIntosh, William Hatton Victoria University of Wellington, New Zealand \\ Danielle Shanahan Zealandia Ltd., New Zealand
}

In the context of the highly compact bicultural capital city of Wellington, New Zealand, this paper explores the development of an ecosanctuary initiated by the community. The indigenous flora and fauna was damaged as a result of the introduction of mammalian predators and aggressive plant species when the country was colonized, and through intensive urbanization. The restoration of the indigenous flora and fauna and the reintroduction of birdsong has resulted in a significant increase in commercial ecotourism. This paper explores health and well-being opportunities resulting from seeing the sanctuary through a Māori lens. It examines the phenomenon of Zealandia, where green and blue infrastructures foster emerging ecologies while accommodating visitor services and improving the social, cultural, economic, and environmental health of the city. It finds that the benefits of this compact urban landscape far exceed the original goals of the project and it offers new prospects for health and well-being through intensification by addressing sustainability holistically and including sociocultural perspectives and initiatives.

Indigenous knowledge / biculturalism / ecosanctuary /

Zealandia / health and well-being

\section{Introduction}

Introduced as an alternative to urban sprawl, the concept of the compact city focuses on limiting the peripheral expansion of urban areas, and instead looks to direct development in the form of intensification by increasing the densities of existing central urban areas. However, while the reduction of sprawl saves on the cost of items such as energy, servicing, and transportation, the intensification associated with urbanization destroys natural landscapes and devastates rich indigenous ecologies. ${ }^{1}$ The juxtaposition of housing and related built infrastructure with very limited interstitial space can pose a major threat to biodiversity and human health. Urban green spaces are generally small, isolated, or unevenly distributed, appearing in different shapes and sizes. This paper examines the development of urban green spaces within the compact city by exploring alternative understandings of landscape through the use of a bicultural lens. It acknowledges that urban living comes with multiple pressures, including the lack of green spaces in the city due to the high demand and reliance on built infrastructure, and the growth in population in urban centres. It also reflects on the more social aspects of urbanization, such as the disregard and loss of past cultural influences and the constant pressures of city living, which lead to poorer mental well-being. ${ }^{2}$ The need to connect with the landscape is now higher than ever before as individuals suffer from a progressively limited access to nature. ${ }^{3}$ 


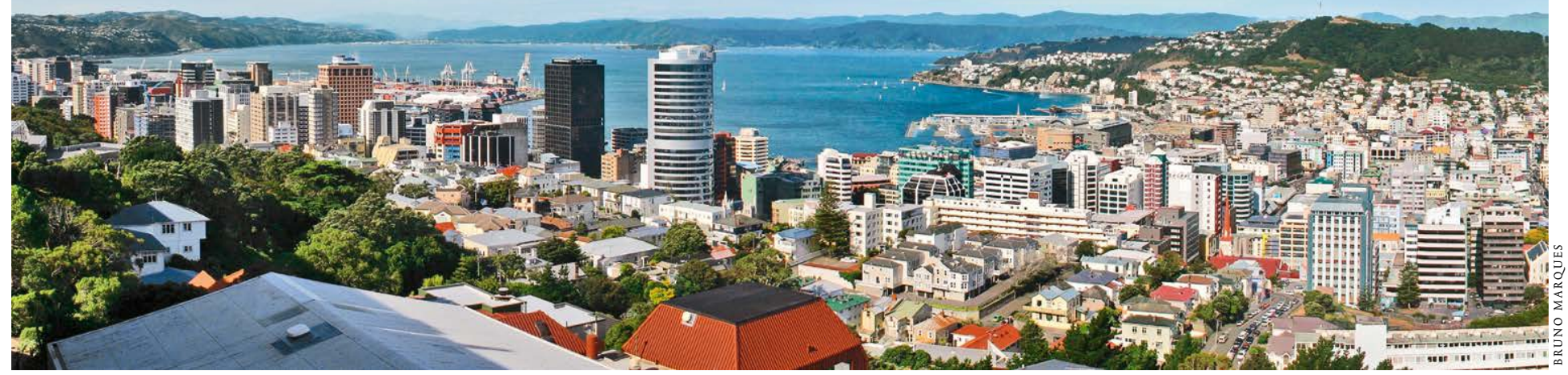

Figure 1 Wellington's waterfront and rugged topography

Compared with many countries internationally, New Zealand is not the first to come to mind when thinking about compact cities. However, due to the rugged topography and the extensive waterfront, its capital Wellington is confronted with the necessity for compactness in the face of its geography (Fig. 1). The city has a natural tendency towards physical containment, with an amphitheatre of hills leading down to the harbour. It maintains a wider policy of containment and general intensification of suburban development, which anticipates that the majority of residential growth will be located within the existing urban area. As the capital, Wellington is also aware of its responsibilities with respect to national goals of biculturalism and in honouring the basic tenets of Te Tiriti o Waitangi (Treaty of Waitangi), which establishes that Māori culture must not only be recognized and re-established, but fully integrated into all aspects of society in a manner that is respectful and meaningful for both cultures.

\section{Understanding biculturalism}

The Mãori, like many other Indigenous peoples, were suppressed by Western constructs that have influenced the way they relate to landscape. This situation was exacerbated as the Māori moved from their ancestral lands into dense urban centres, separating them from their land-based roots and culture. Currently, 88 per cent of the Māori population live in these urban centres. ${ }^{4}$ Restoring the cultural values of landscape in a bicultural country is an essential but often overlooked necessity for the intensification that accompanies the creation of a truly sustainable compact city. ${ }^{5}$

The two New Zealand cultures have considerable differences with respect to cultural, economic, and ecological values. The Western understanding of land and landscapes is strongly influenced by a positivistic, scientific, and utilitarian relationship between people and land. ${ }^{6}$ Thereby, knowledge is seen as rational and goal-oriented and the world is understood as a single layered construct of universal principles where humans are superior to all other living creatures, and pursue material assets. ${ }^{7}$ For Māori, human beings live in unison with nature, following a more holistic, experiential and belief-based approach that emphasizes the unique rather than the transcendental. ${ }^{8}$ This article focuses on the collision of these two cultures and their respective values in the development of a nature sanctuary that seeks to restore the landscape to its pre-occupation condition. It presents the history of the development of Zealandia, a world-first fenced wildlife sanctuary, the solutions and strategies faced, and the pathways going forward. Due to its central location in Wellington, Zealandia is seen as a catalyst for strategic integration of nature into our urban environments. It posits that a native urban ecosystem in a bicultural country can generate new ways of thinking about landscape in the compact city that expand beyond commercial models to a rich multifaceted exploration of people and nature as a union. While the philosophical frameworks of improvement ${ }^{9}$ or theorizations on capitalism ${ }^{10}$ assist in understanding the richness and complexity of Western thinking, there are few equivalent explanations of indigenous ways of knowing.

\section{Historical background}

Prior to the arrival of humans, Aotearoa/New Zealand was a 'bird land', isolated and unique. Deprived of mammalian predators, an ecosystem of remarkable flora and fauna had evolved where forests made up 60 per cent of the natural landscape. The endemic ecology supported and benefited the Māori both physically and spiritually; however, while the Māori revered the landscape, they were responsible for the introduction of the kiore (Polynesian rat) and the extinction of the moa, as well as the clearing of small pockets of forest for cultivation. ${ }^{11}$

Colonization saw the introduction of mammalian predators and invasive plant species, resulting in the extinction of native biodiversity, and broad-scale clearing, which scarred and reshaped the landscape. ${ }^{12}$ In the last 800 years, the loss of indigenous flora and fauna is inestimable, but approximately half of all vertebrates have become extinct (Fig. 2). Wellington 


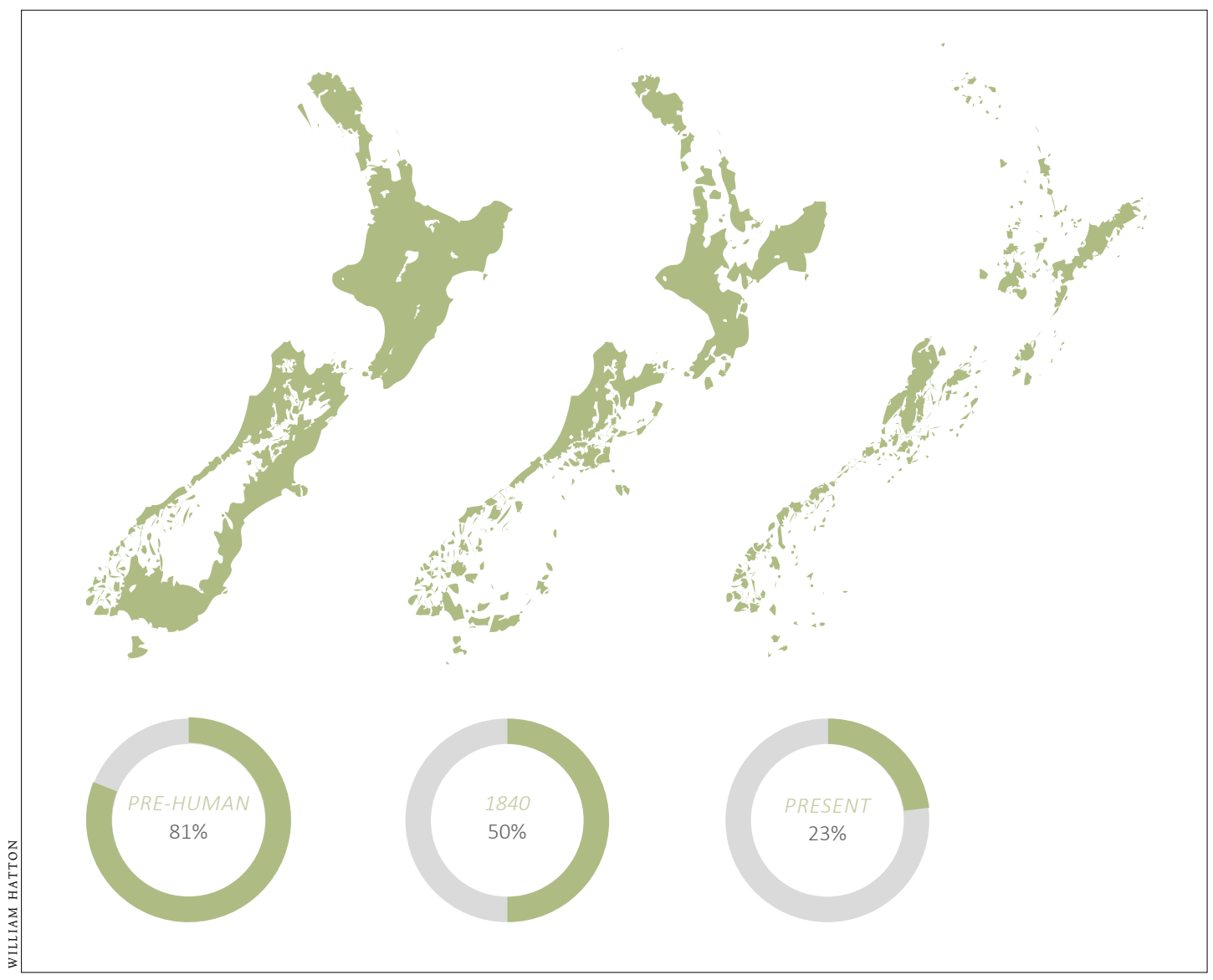

Figure 2 Deforestation of Aotearoa/ New Zealand and the remaining indigenous forest once thrived in vast swamp marshlands and dense podocarp forests made sustainable food-hubs for early Māori settlements. However, with the arrival of European settlers around 1840, a comprehensive programme of forest, swamp, and wetland clearing for logging, grazing, and farming ensued. Within the city boundaries, the Karori valley system was a highly prized area as it contained gold and other lucrative minerals, offered fertile land for grazing and agriculture, and had abundant supplies of water. The valley became an important water supply for the area and accommodated two constructed reservoir systems (Fig. 3). As the geology of the valley became better understood, a major earthquake fault line was identified running directly under the new reservoirs, necessitating their replacement. Over time, the amenity of the Karori valley changed because of urbanization, turning it into a wild and weedy scrubland (Fig. 3).

In the early 1990s, in an effort to 'bring back the birds to Wellington', local residents developed a strategic plan to 'preserve and enhance the natural treasures of Wellington City'. ${ }^{13}$ Establishing a non-profit charitable trust allowed the community to participate in the development of a sanctuary. An unutilized water reservoir system created the opportunity for a sanctuary in the compact inner suburbs of the capital and the decision was made to design a predator-proof fence surrounding the 225-hectare site that excluded mammalian predators, with construction commencing in 1999. The fence is $2.2 \mathrm{~m}$ high, $8.6 \mathrm{~km}$ long, with a 3 -m-wide clear track next to it to stop jumping animals (Fig. 4). The fence itself is made of tight wire weave mesh with the largest gap being 6 x $50 \mathrm{~mm}$, which excludes most mammals (except mice). A woven mesh skirt extends outwards below the ground for $400 \mathrm{~mm}$, to create an effective barrier to burrowing animals. Public entrance to the sanctuary valley is through a heavily monitored doublegate entrance. To address the possibility of mechanical failure, breaches of the fences, or subsidence allowing reinvasion, strategies to detect and control reinvasions have been implemented. Ongoing monitoring of the fence, ground, and vegetation is an important part of the management plan. Following the construction of the perimeter fence, the world's first eradication plan targeting thirteen species at once was begun. ${ }^{14}$

Today Zealandia is the world's first fully-fenced urban ecosanctuary. ${ }^{15}$ The ultimate 500-year restoration goal is to create self-sustaining forest and freshwater ecosystems, representative of the prehuman state that existed in Aotearoa/New Zealand approximately 1,00o years ago, and to restore the indigenous character of the valley. The restoration of native forest provides habitat for the re-establishment of wildlife species that have disappeared. Forest giants like rātā, rimu and miro, which are rare or missing, are being planted to replace exotic trees such as pine and restore soil composition (Fig. 5). The action of replacing exotics with native species creates a mutually beneficial environment, as several of the most important tree species (such as tawa and miro) provide an essential food source for the native birds and in return the native trees rely almost entirely on birds for the transport of their seed. 'The extinction or decline of several [native] bird species 


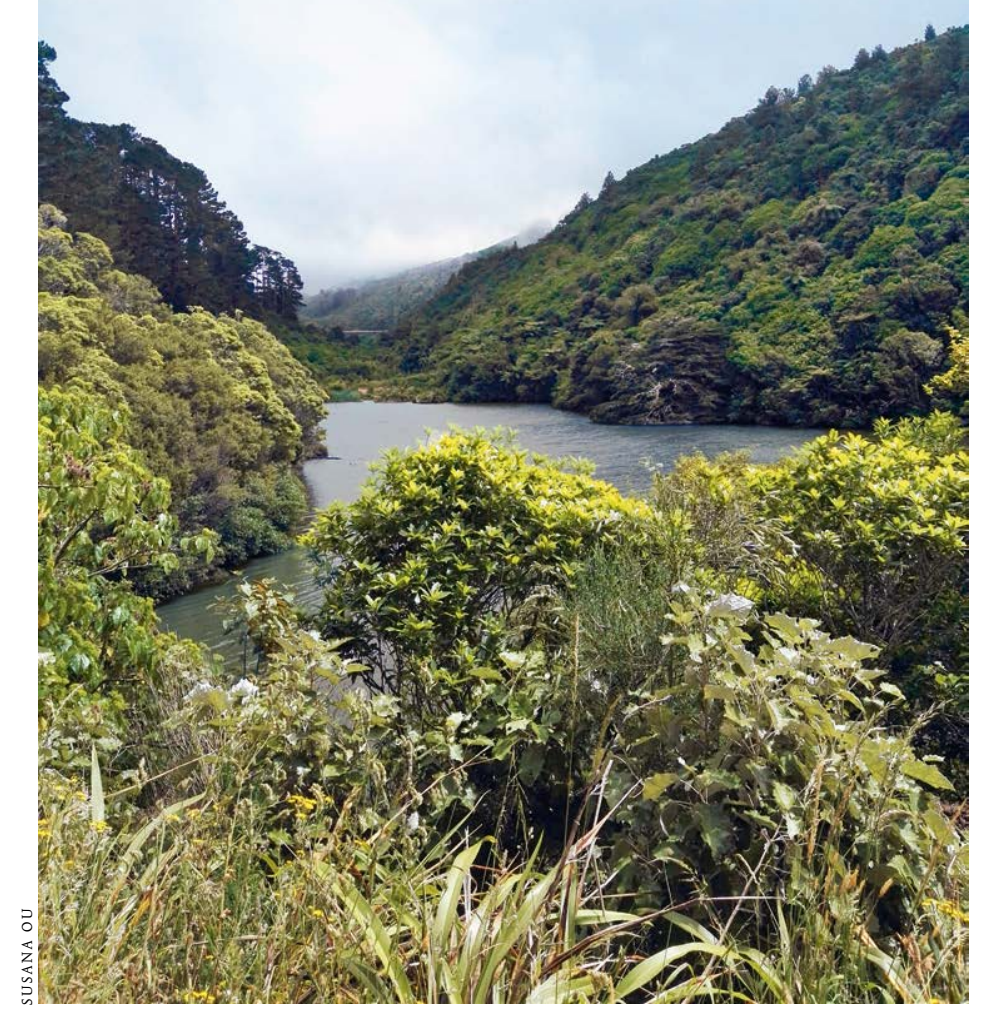

Figure 3 The Zealandia sanctuary and the Karori Upper Dam

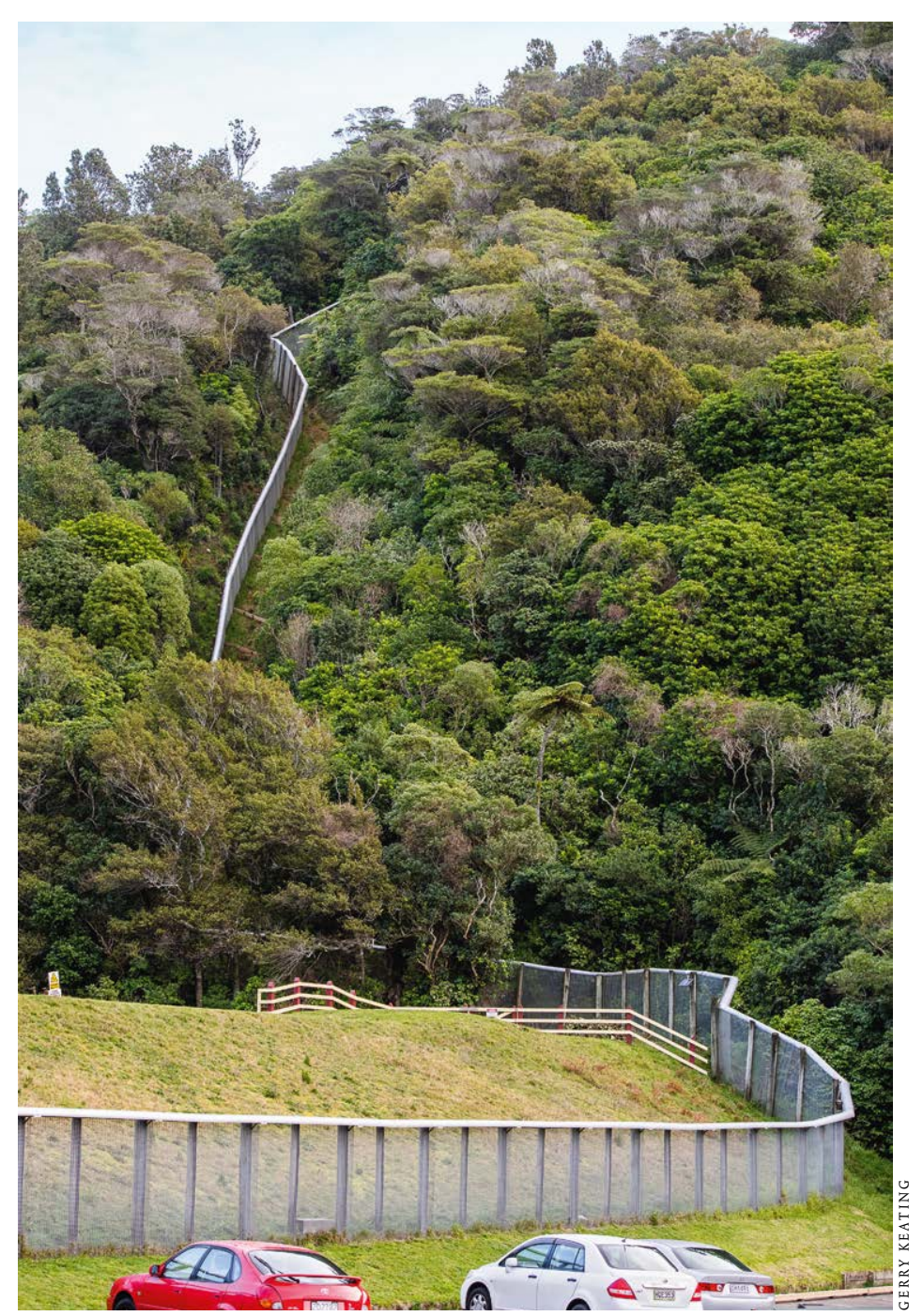

Figure 4 Predator-proof fence surrounding the ecosanctuary
Figure 5 Remnant of an exotic forest of pine trees (top) and the emergent native flora (bottom)

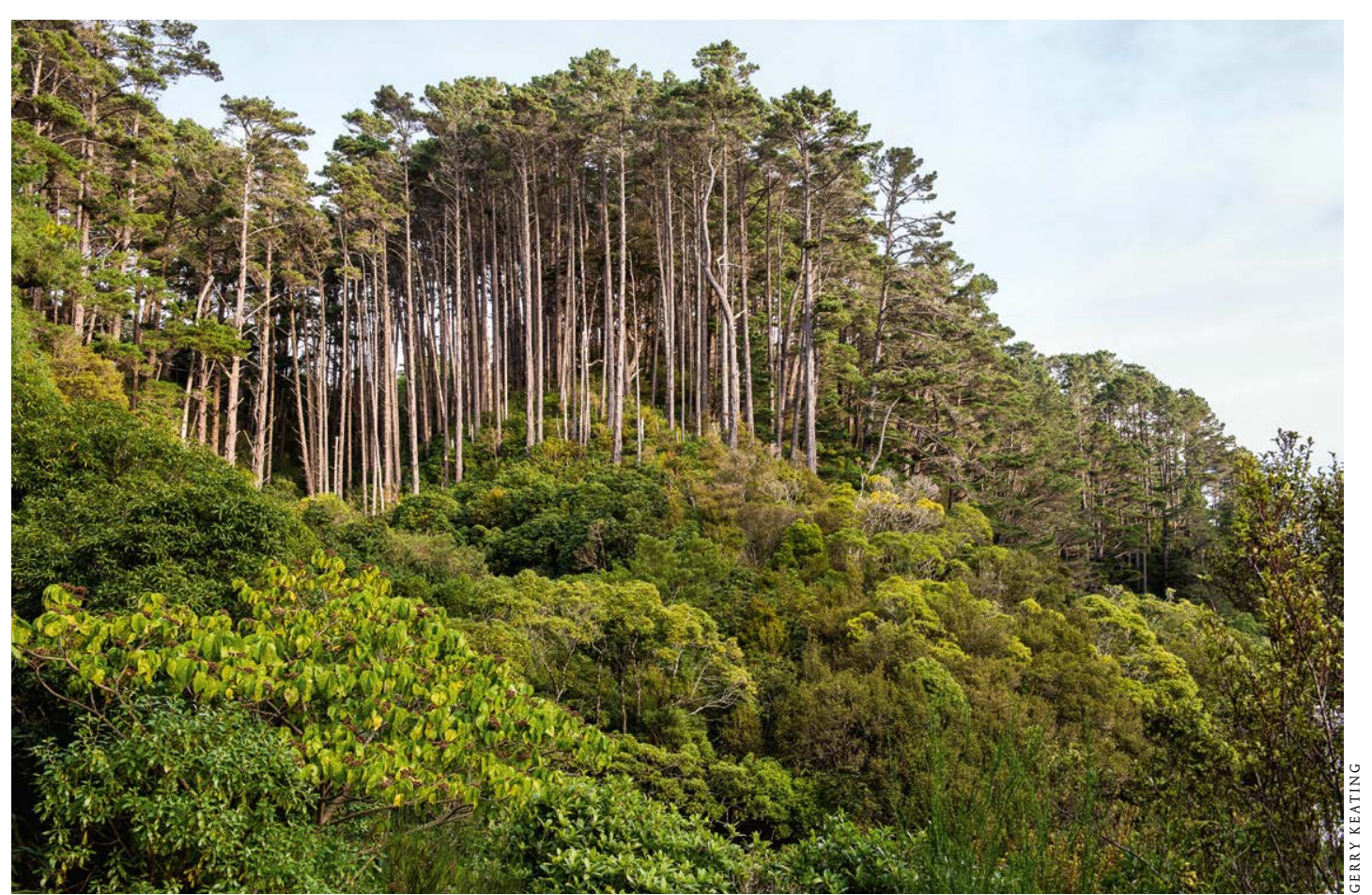




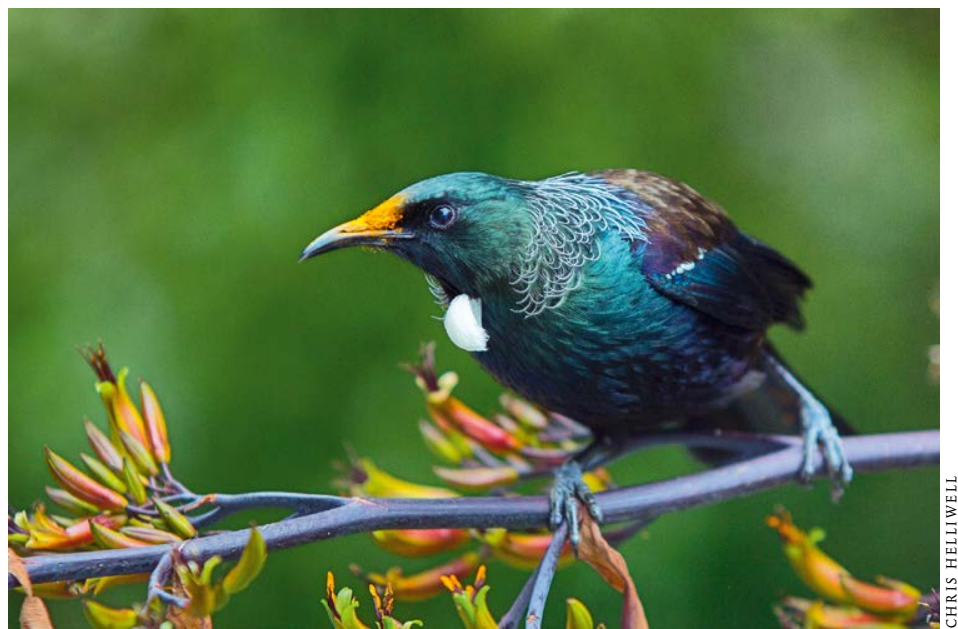

Figure 6 Tui, or Prosthemadera novaeseelandiae, is an endemic bird of New Zealand and one of the largest species of the honeyeater family. They have blue, green and bronze iridescent sheen, and distinctive white throat tufts.

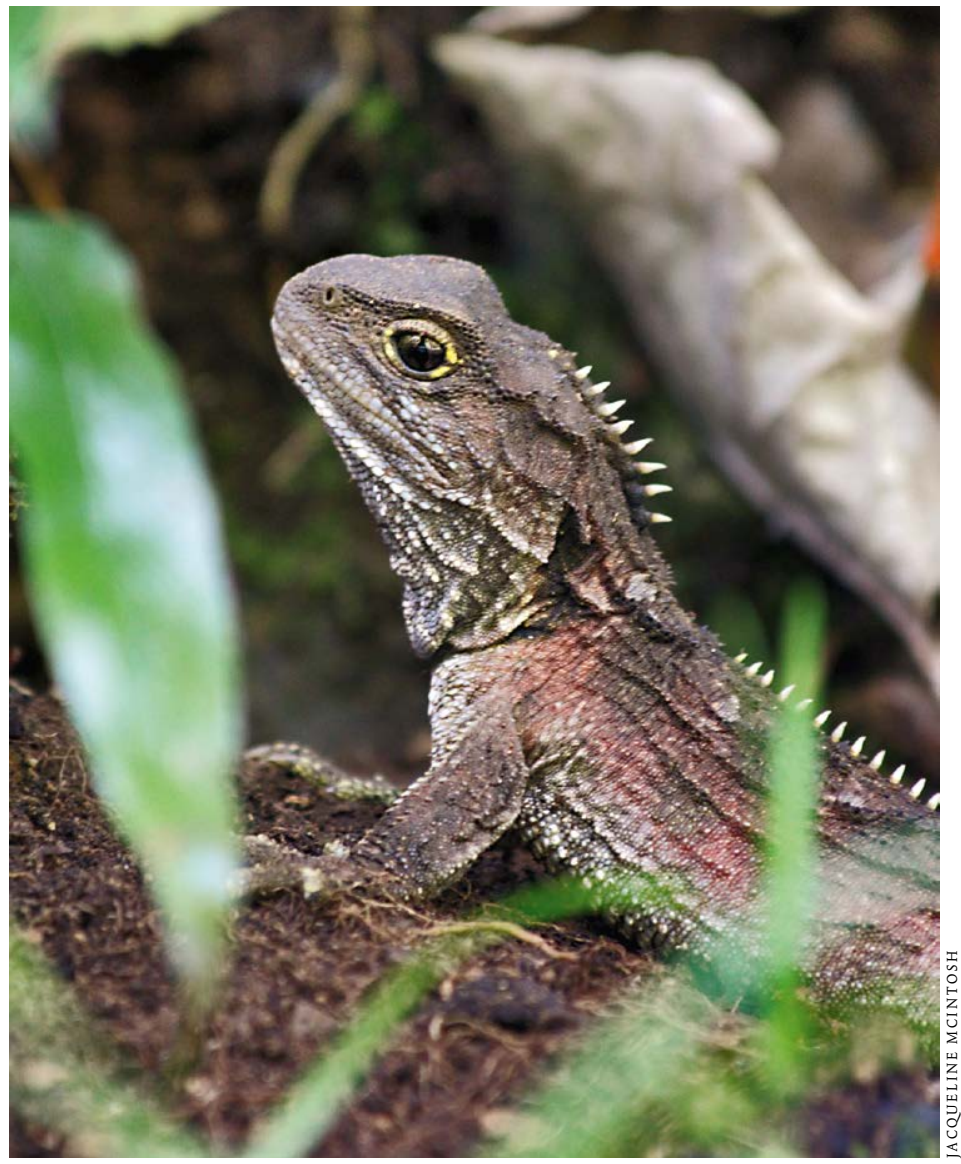

Figure 7 Tuatara, or Sphenodon punctatus, are rare, medium-sized reptiles found only in New Zealand. They are the last survivors of an order of reptiles that thrived in the age of the dinosaurs.

\section{Bicultural perspectives on landscape}

This study adopts a correlational approach. Within the general framework of correlational research, it follows a relationship subtype focusing on the two cultures of Aotearoa/New Zealand rather than the causal-comparative correlational research subtype. "While all correlational studies seek to describe relationships among key variables, relationship studies focus more specifically on the nature and predictive power of such relationships. ${ }^{20}$ The Māori are concerned about the accountability of researchers, and who or what controls the creation and distribution of knowledge about Māori. ${ }^{21}$ For non-Māori academics, it is important that researching authors acknowledge any lack of Indigenous heritage and recognize the commitment to support Māori research as Treaty of Waitangi partners. ${ }^{22}$ Methodologically, it is important to ensure authenticity and accuracy through engagement with Māori in the community of practice and peerreview by the Indigenous group represented. This study considers the success of Zealandia through two different cultural lenses, that of the European and that of the Māori; it then compares them with respect to their contribution to landscape.

From a non-Māori perspective, the Karori valley has been a highly successful asset from the beginning of settlement to the current day. When settlers established the area in 1842 , the land quickly obtained a reputation for being the best dairy land in Wellington. In addition, the soil structure 


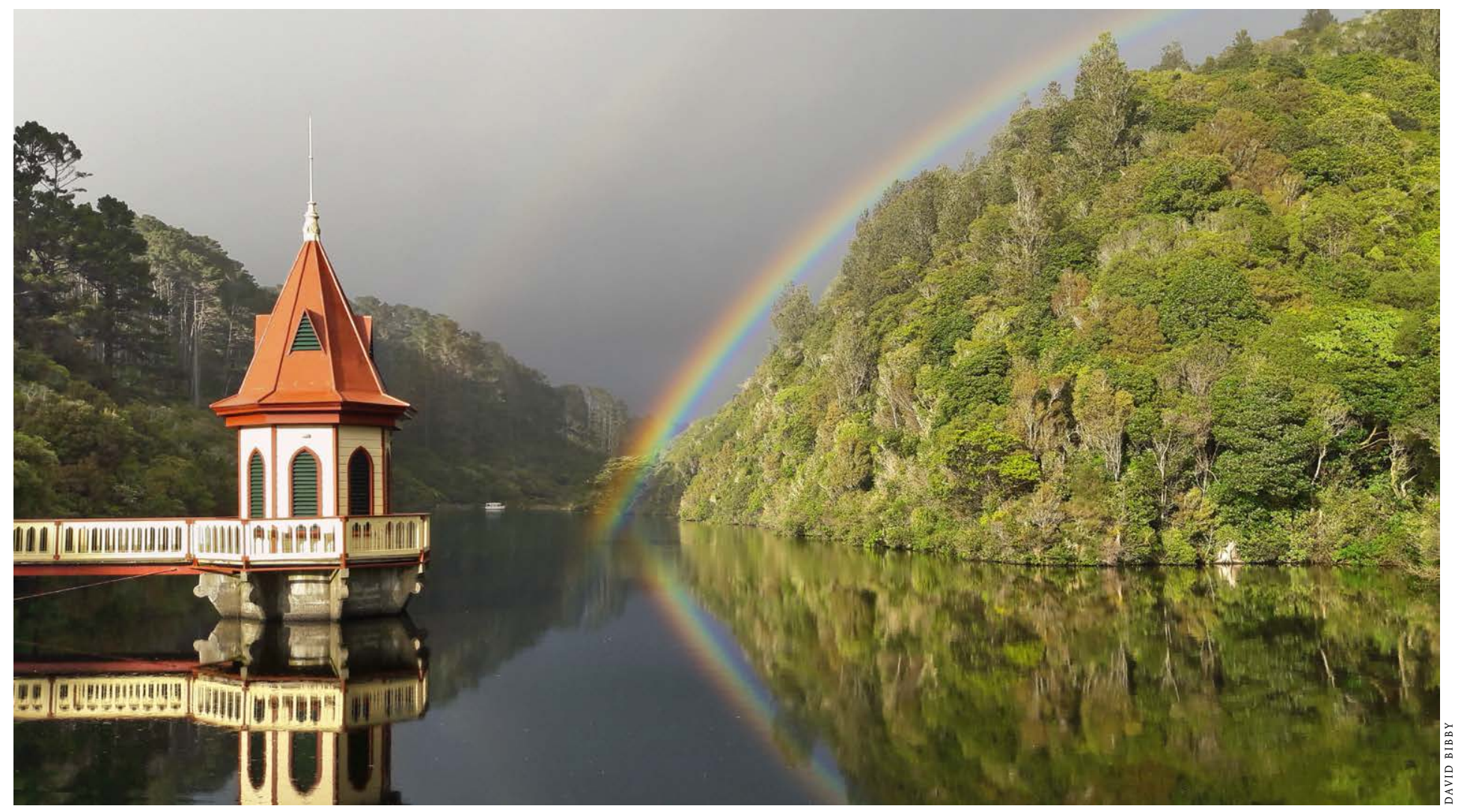

Figure 8 Zealandia sanctuary and the Lower Karori Dam

had highly drained soils making it easy to use for agriculture. ${ }^{23}$ The dense forest and bush with large tracts of kahikatea, miro, matai (black pine), totara, and rimu were cut, milled, and exported to the United States and Australia, and used for local construction. Cattle and sheep grazing across the valley rapidly increased where most of the original native species were lost. ${ }^{24}$

With population growth, the demands for freshwater increased. The Kaiwharawhara stream elevation allowed water to flow by gravity to the central town. ${ }^{25}$ Ongoing growth and demand for water led to the construction of the Lower Karori Dam, which changed the natural water structure along the valley floor (Fig. 8). As the demand for water continued to outpace the supply, a second dam was constructed and chemical treatment of the water commenced. ${ }^{26}$ However, advances in engineering and seismology established that the dams were precariously positioned above the Wellington faultline. Major concerns about the water quality and overall public safety led to the decommissioning of the dams in 1991 and $1997^{27}$ and the future of the land came into question.

From a Māori perspective however, the history of the Karori valley can be seen as a metaphor for colonization, where life-giving landscapes were seriously tampered with for commerce and economic consumption. ${ }^{28}$ Today, the Māori make up only 7 per cent of Wellington's population, whereas mana whenua (local Mãori ) make up just 7 per cent of that 7 per cent (Fig. 9). ${ }^{29}$ With respect to landscape, the Mãori historically looked to it as a medium for physical, emotional, mental, and spiritual health and well-being. Māori philosophy considers an inclusive 'whole of landscape' approach known as ki uta ki tai (to the mountains to the sea). It is a philosophy that reflects on a system of environmental and resource management that celebrates guardianship and reflects the relationship of environmental heritage. ${ }^{30}$
Landscapes are thereby a representation of identity and values for the Māori, grounding people through the interconnectedness of cultural and intergenerational ideals and perceptions with the land. ${ }^{31}$ The traditional Mãori idea that people are born from the earth sets a foundation for the kinship between man and nature. From this understanding, practices evolved that establish a tangible connection to the land and allow people to reflect on their own identity and belonging in the world. Identity is established through whakapapa (lineage) and connected by mauri (life force) to the mountains, bodies of water, and ancestral lands, the knowledge of which is conveyed regularly at community gatherings. The combination of social, cultural, economic, and ecological factors aims to benefit and support both the land and its people and living with nature implies the guardianship of both land and people as sacred. ${ }^{32}$

Despite its Western origins, Zealandia now offers a unique platform for the exploration and development of a truly bicultural landscape. It fosters ki uta ki tai, weaving the landscape to the sea via the Kaiwharawhara stream (Fig. 10) and recreating the underutilized valley system to capture Mātauranga (knowledge) practices and values. The concept of ki uta ki tai considers the environment in its entirety as a holistic construct where all natural systems are linked together, from the understanding of freshwater ecosystems to the health and well-being of the people that are connected to that natural environment. ${ }^{33}$ This concept is formally articulated in Zealandia's strategy 2016-2035 wherein four themes aim to bring Māori values back to the forefront, facilitating a place that 1) treasures, 2) engages, 3) empowers, and 4) provides a place for learning. ${ }^{34}$ The ecological restoration thus includes economic as well as social and cultural sustainability. Considering biculturalism as a way forward, the aim to express and pro- 


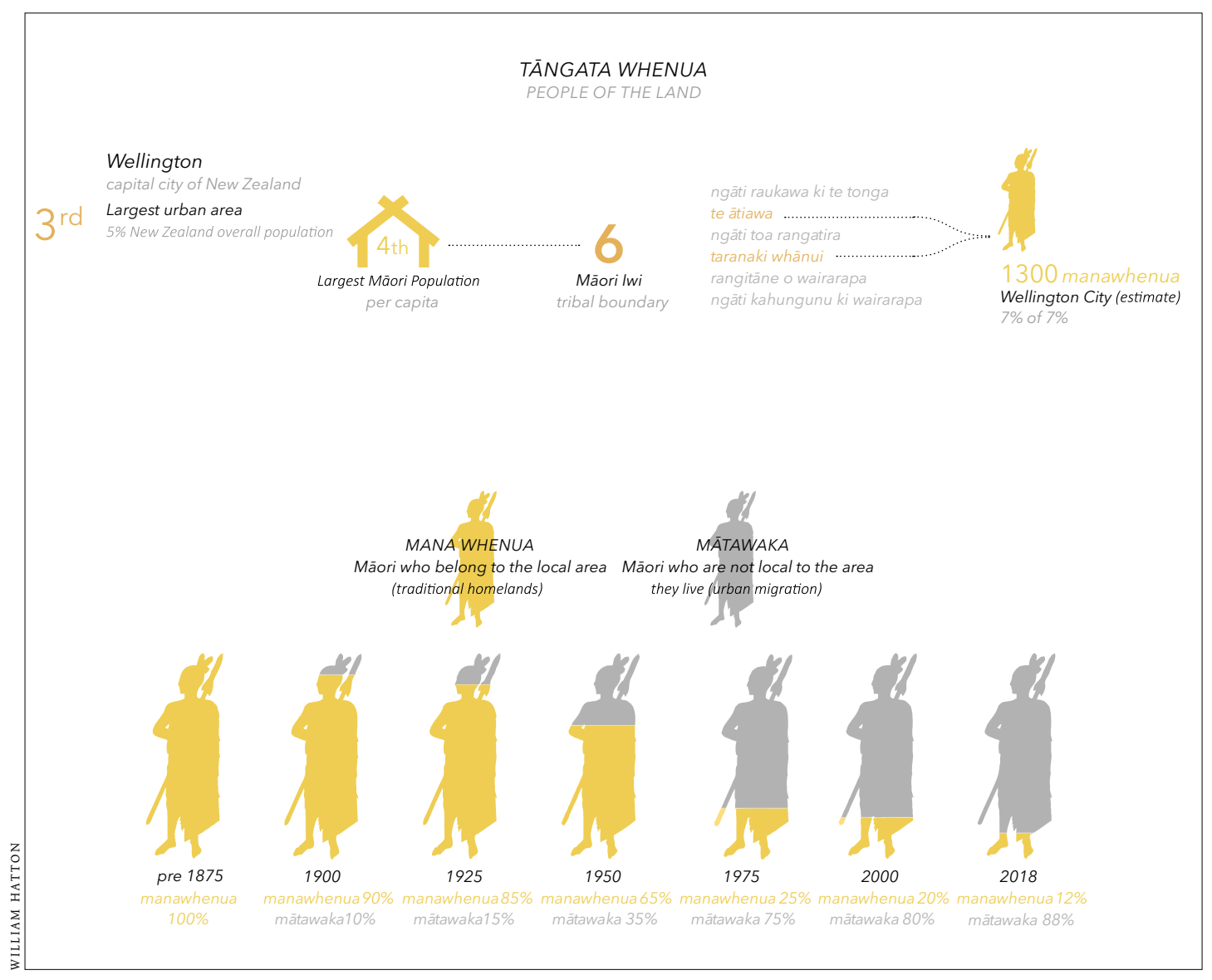

Figure 9 Mana whenua (tribal affiliations) in Wellington City mote Māori knowledge (Mātauranga Māori) and traditions can be a way to find a connection to enhance the environmental values of the waterway in an urban landscape (Fig. 11).

\section{Discussion}

The danger with the drive for a compact city is that the immediate living spaces surrounding urban dwellers have fewer than ideal types of green spaces. Compactness can equate to greater efficiency in land use and the reduction of urban sprawl, but the challenge is to safeguard large natural areas from development pressure. With respect to landscape, efficiency can negate effectiveness. For instance, ten pocket parks are more efficient in terms of achieving higher accessibility for park users, but cannot equate to an ecosanctuary in the ability to provide ecological and health amenity. Increasingly, the need for immersion in the landscape is recognized as beneficial for health and well-being. The pressures of urbanism are linked to public health challenges such as obesity, diabetes, high blood pressure, and even anxiety and depression. A new understanding is forming, accepting the benefits that nature and ecosystems can provide to the society in a compact and urbanized environment. ${ }^{35}$ By using a bicultural lens, the reciprocity of the connection between humans and landscape is recognized as we seek to restore ourselves as we restore the environment.

Zealandia started as a grassroots community participation project seeking to reinstate ecological sustainability, then developed as a commercial tourist attraction in an attempt to address economic sustainability, and now is transforming to consider cultural obligations as it seeks to embrace cultural sustainability. To encompass the duty of sustainable stewardship and repair requires a complex model of governance. No single tool can possi- bly address all of the multicultural dimensions with optimal combinations, while depending on a variety of variables such as the stakeholders involved, financial resources available, and ecological issues at stake. In the compact city financial or social imperatives for the landscape, such as the demand for greater formal recreation areas like skateboard parks or outdoor gyms, often compromise the potential for ecological improvement. Where resource use efficiency is paramount, governance requires new tools to incentivize and coordinate the numerous stakeholders over time.

These influences can be seen in the development of Zealandia. The shifts have allowed movement from a utilitarian perspective to something that is more holistic and that recognizes the relationships between people and nature. It takes into account the importance of cultural values, perspectives, and approaches to the development of sustainable and resilient interactions between human societies and the surrounding environment. ${ }^{36} \mathrm{It}$ also opens the door for an exploration of what it means to develop landscape in a cultural context with the intensification that occurs with city compaction. Successful and sustainable landscape planning and design in a compact urban context demands a multifaceted understanding of man and nature as an interdependent union.

Another salient lesson in the face of the multiplicities of compactness is the necessity for close and inclusive cooperation-in this case study, cooperation with Indigenous as well as local communities, and environmental groups when facilitating a bottom-up process. 'Eco-restoration is not simply a scientific endeavour, its success usually also requires community support and participation. ${ }^{37}$ Taking a multicultural, and in this case Māori perspective, can help human beings regain a physical, emotional, and spiritual connection to nature. 


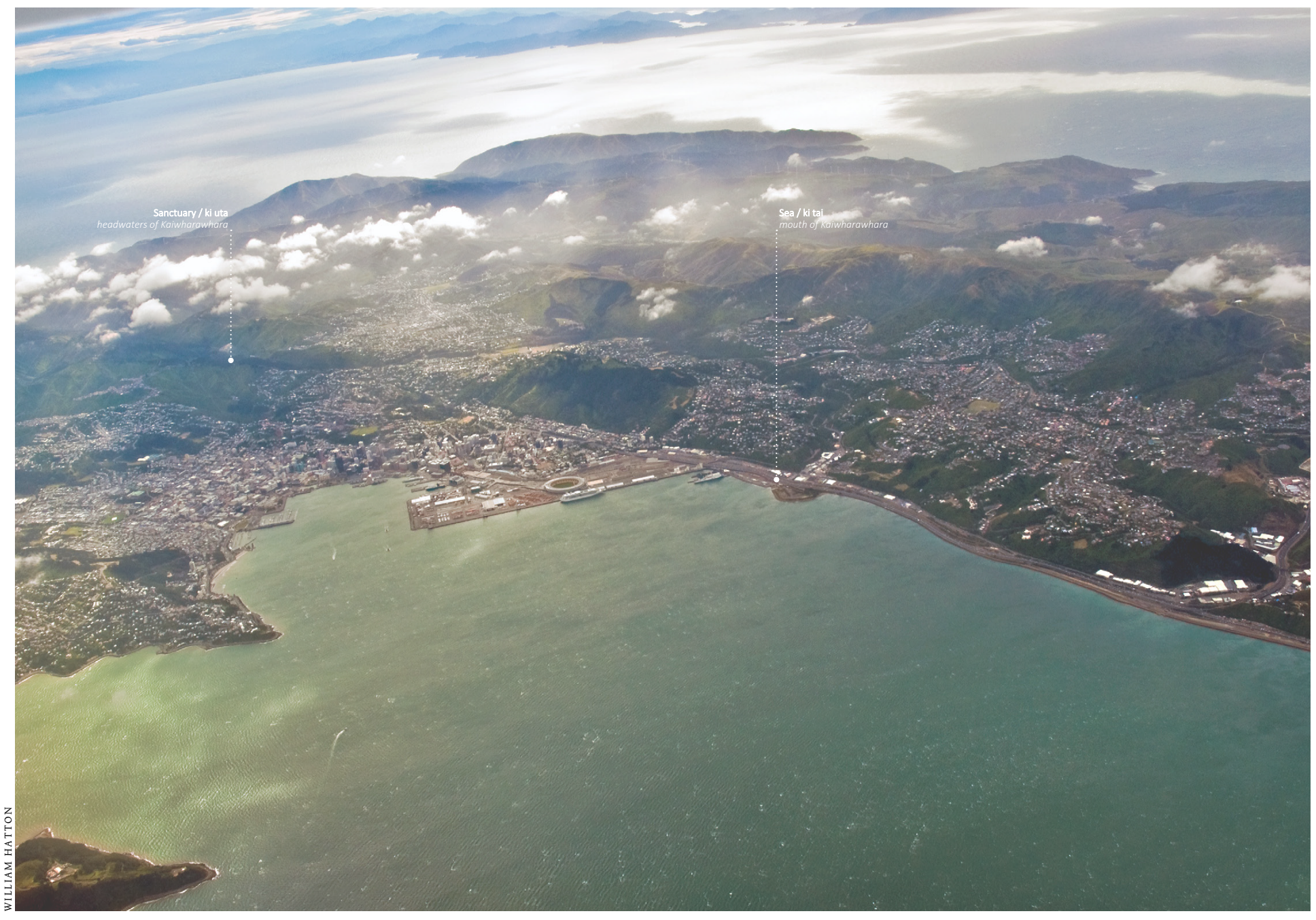

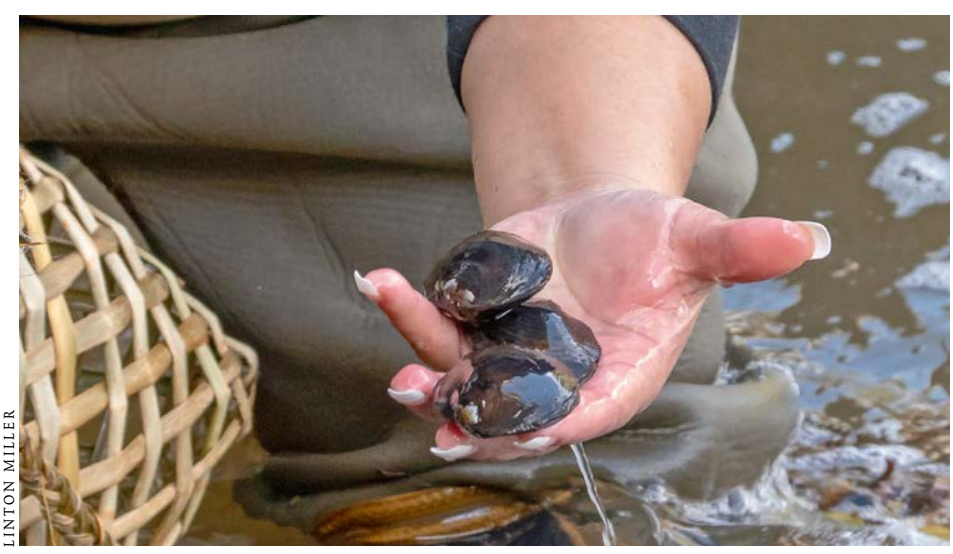

Figure 11 The ceremonial reintroduction of kākahi (native freshwater mussels) into the sanctuary for natural water purification
Figure 10 Ki uta ki tai, from the sanctuary to the sea

\section{Conclusion}

In the context of the compact city, connecting with natural landscapes offers an opportunity to counter the negative effects of urbanization on people's lives, as it provides physical, mental, and social well-being benefits. ${ }^{38}$ To complement the array of pocket parks and small urban green spaces, inner suburban island sanctuaries made free of threats to biodiversity are becoming increasingly common, establishing a novel approach to wildlife protection in the green spaces of compact urban cities. ${ }^{39} \mathrm{New}$ Zealand's first ecosanctuary, Zealandia, developed from a bottom-up local initiative, through a commercially focused tourist attraction, to a sustainably orientated bicultural, municipally owned and operated trust. In this example, Zealandia has provided a unique opportunity for the reintroduction and conservation of native flora and fauna, but also the reintroduction and preservation of Mātauranga Māori (Indigenous knowledge), elaborating on values and traditions, and identifying places and processes through which it can be enacted. Developing Zealandia with a view through each of New Zealand's cultural lenses can transform the way we think at local, national, and international levels. ${ }^{40}$ 
In this regard, Zealandia is successful in a number of firsts where the objective of pest eradication allowed for ongoing recovery and restoration of an endemic self-sustaining ecosystem. ${ }^{41}$ Re-establishing flora and habitats representative of the Wellington area's historical coastal lowlands and freshwater ecosystems can ensure that key natural processes function in the enclosed sanctuary. ${ }^{42}$ The lessons learned and the tested methodologies can be applied elsewhere in similar national recovery programmes ${ }^{43}$ and the benefits to date have already far exceeded the community's expectations.

The Zealandia concept plan has also enabled native fauna and flora to return and thrive in close proximity to the compact city centre, conceiving the city fringe as a haven of ecological importance. Nature perceived as sustainable conservation and guardianship has helped restore the natural processes and create a catalyst for community involvement while bringing back the natural taonga (treasures) of tangata whenua (the Indigenous people). It has also facilitated learning about our natural heritage and advancing knowledge and techniques for the conservation of ecological and cultural systems. ${ }^{44}$

The case study of Zealandia elaborates on strategies and unique ways to acquire and sustain our natural environment in the context of the compact city. This rich connection can equip people with experiences and skills that inspire change and develop a passion for action when preserving the endemic natural heritage. The idea of connectedness is an important underlying value that relates people to the environment and the environment to the people, thereby enhancing the sense of guardianship to the land and encouraging different ways of thinking to flourish in mutual respect. If cities are to move forward, an appreciation for the importance of the natural environment must be acknowledged as essential for health and wellbeing. Weaving traditional ways of knowing with modern ways of thinking allows people and nature to thrive reciprocally.
NOTES

1 Michael McKinney, 'Urbanization, Biodiversity, and Conservation', Bioscience 52/10 (2002), 883-890.

2 Erik Andersson, 'Urban Landscapes and Sustainable Cities', Ecology and Society 11/7 (2006), 531-545; Melinda Moore, Philip Gould, and Barbara Keary, 'Global Urbanization and Impact on Health', International Journal of Hygiene and Environmental Health 206/4 (2003), 269-278; Kristina Sundquist, Gölin Frank, and Jan Sundquist, 'Urbanisation and Incidence of Psychosis and Depression: Follow-up Study of 4.4 Million Women and Men in Sweden', The British Journal of Psychiatry 184/4 (2004), 293-298.

3 Daniel Cox et al., 'The Rarity of Direct Experiences of Nature in an Urban Population', Landscape and Urban Planning 160 (2017a), 79-84; Masashi Soga and Kevin Gaston, 'Extinction of Experience: The Loss of Human-Nature Interactions', Frontiers in Ecology and the Environment 14/2 (2016), 94-101.

4 Statistics New Zealand, 'New Zealand: An Urban/Rural Profile', archive.stats.govt.nz/ /media/Statistics/browse-categories/maps-and-geography/geographic-areas/urban-ruralprofile/maps/nz-urban-rural-profile-report.pdf, accessed 18 June 2018.

5 Jacqueline McIntosh, Bruno Marques, and William Hatton, 'Indigenous Cultural Knowledge for Therapeutic Landscape Design', in: Isabel Sousa Rosa et al. (eds.), Handbook of Research on Methods and Tools for Assessing Cultural Landscape Adaptation (Hershey, PA: IGI Global, 2018), 28-52.

6 Richard Peet and Michael Watts, 'Liberation Ecology: Development, Sustainability, and Environment in an Age of Market Triumphalism', in: Richard Peet and Michael Watts (eds.), Liberation Ecologies: Environment, Development, Social Movements (New York: Routledge, 1996), 3-47.

7 Wang Shik Jang, 'A Philosophical Evaluation of Western and Eastern Civilisations from a Whiteheadian Perspective', Process Studies 33/1 (2004), 135-148.

8 Diane Menzies, Alayna Renata, and Desna Whaanga-Schollum, 'Connecting Eco-Systems and Belief Systems through Regeneration and Innovation', in: IFLA Americas Regional Conference: Science and Consciousness in Landscape (La Paz: Bolivian Institute of Landscape Architects, 2015), 67-82.

9 Asa Briggs, The Age of Improvement, 1783-1867 (London: Routledge, 1999); Jack Larkin, 'From "Country Mediocrity” to "Rural Improvement": Transforming the Slovenly Countryside in Central Massachusetts, 1775-1840', in: Catherine Hutchins (ed.), Everyday Life in the Early Republic (Charlottesville, VA: University of Virginia Press, 1992), 175-200.

10 David Harvey, The Enigma of Capital: And the Crises of Capitalism (Oxford, UK: Oxford University Press, 2010).

11 Kevin Jones, A Guide to Wellingtons Māori History, nga korero mua o Te Upoko O Te Ika (Wellington: Historic Places Trust, 1986).

12 Marie Brown et al., Vanishing Nature: Facing New Zealand's Biodiversity Crisis (Wellington, New Zealand: Environmental Defence Society, 2015).

13 Karori Wildlife Sanctuary, Restoration Strategy (Wellington: Karori Wildlife Sanctuary, 200o); Karori Wildlife Sanctuary, Valley Management Plan (Wellington: Karori Wildlife Sanctuary, 2000). 
14 Bruce Burns, John Innes, and Tim Day, 'The Use and Potential of Pest-Proof Fencing for Ecosystem Restoration and Fauna Conservation in New Zealand', in: Michael Somers and Matthew Hayward (eds.), Fencing for Conservation (New York: Springer, 2012), 65-90.

15 Paul Star, 'Island Reserves and Mainland Islands, Including a Review of Eco-Sanctuaries', Environment and Nature in New Zealand 9/2 (2014), 61-70.

16 Mick Clout and Rod Hay, 'The Importance of Birds as Browsers, Pollinators and Seed Dispersers in New Zealand Forests', The New Zealand Journal of Ecology 12 (1989), 27-33

17 Saren Starbridge, 'Journeys That Connect', Wildlife Australia 47/2 (2010), 2 .

18 Raewyn Empson and Denise Fastier, 'Translocations of North Island Tomtits (Petroica macrocephala toitoi) and North Island Robins (P. longipes) to Zealandia-Karori Sanctuary, an Urban Sanctuary: What Have We Learned?', Notornis 60/1 (2013), 63-69.

19 Karori Wildlife Sanctuary, Restoration Strategy, op. cit. (note 13); Andrew Tanentzap and Kelvin Lloyd, 'Fencing in Nature? Predator Exclusion Restores Habitat for Native Fauna and Leads Biodiversity to Spill over into the Wider Landscape', Biological Conservation 214 (2017), 119-126.

20 Linda Groat and David Wang, Architectural Research Methods (New York: Springer, 2002).

21 Russel Bishop, 'Addressing Issues of Self-Determination and Legitimation in Kaupapa Maori Research', in: Bev Webber (ed.), He Paepae K rero: Research Perspectives in Mãori Education (Wellington: New Zealand Council for Educational Research, 1996), 142-160.

22 McIntosh, Marques, and Hatton, 'Indigenous Cultural Knowledge', op. cit. (note 5), 28-52.

23 Judith Burch, The Karori Reservoir Area, a Brief History (Wellington: The Karori Society, Ashford Print Ltd, 1997).

24 Mick Clout, "Where Protection Is Not Enough: Active Conservation in New Zealand', Trends in Ecology \& Evolution 16/8 (2001), 415-416.

25 Peter Cooke, Our Water History: On Tap: Water Supply in the Wellington Region 1867-2006 (Wellington: Greater Wellington Regional Council, 2007).

26 Karen Astwood and Georgina Fell, Karori Water Supply Dams and Reservoir (Wellington: IPENZ Engineers New Zealand, 2012).

27 Cooke, 'Our Water History', op. cit. (note 25), 14.

28 Amy Davis, 'For Beauty and Health: Nature and Environment in Suburban Karori', in: James Beattie (ed.), Environment and Nature in New Zealand (Hamilton: University of Waikato, 2011), 1-23.

29 Keriata Stuart, Iwi Kainga Participation in Urban Development (Dunedin, NZ: Otago University, 2016).

30 Keriata Stuart and Michelle Thompson-Fawcett, Taone tupu ora, Indigenous Knowledge and Sustainable Urban Design (Wellington: Astra Ltd, 2010).
31 Bruno Marques, Greg Grabasch, and Jacqueline McIntosh, 'Fostering Landscape Identity through Participatory Design with Indigenous Cultures of Australia and Aotearoa/New Zealand', Space and Culture (2018), 1-16.

32 Bruno Marques, Jacqueline McIntosh, and William Hatton, 'Haumanu ipukarea, ki uta ki tai: (Re)connecting to Landscape and Reviving the Sense of Belonging for Health and Wellbeing', Cities \& Health 2/1 (2018), 82-90.

33 Gail Tipa, 'Exploring Indigenous Understanding of River Dynamics and River Flows: A Case from New Zealand', Environmental Communication 3/1 (2009), 95-120.

34 Zealandia, 'Zealandia's Strategy 2016-2035', www.visitzealandia.com/livingwithnature, accessed 31 July 2018.

35 Georgina Mace, 'Whose Conservation?', Science 345/6204 (2014), 1558-1560.

36 Ibid.

37 Dave Egan, Jesse Abrams, and Evan Hjerpe, 'Synthesis: Participation, Power, Perspective', in: Dave Egan, Evan Hjerpe, and Jesse Abrams (eds.), Human Dimensions of Ecological Restoration: Integrating Science, Nature and Culture (Washington, DC: Island Press, 2011), 375-383.

38 Daniel Cox et al., 'Doses of Nearby Nature Simultaneously Associated with Multiple Health Benefits', International Journal of Environmental Research and Public Health 14/2 (2017b), 172-185; Danielle Shanahan et al., 'Variation in Experiences of Nature across Gradients of Tree Cover in Compact and Sprawling Cities', Landscape and Urban Planning 157 (2017), 231-238; Danielle Shanahan et al., 'The Health Benefits of Urban Nature: How Much Do We Need?', Bioscience 65/5 (2015), 476-485.

39 John Craig et al., 'Conservation Issues in New Zealand', Annual Review of Ecology and Systematics 31/1 (2000), 61-78; James Russell et al., 'Invasive Alien Species on Islands: Impacts, Distribution, Interactions and Management', Environmental Conservation 44/4 (2017), 359-370.

40 Zealandia, Annual Report 2015/16 (Wellington: Zealandia, 2016).

41 Karori Wildlife Sanctuary, Some Thoughts on Predator Exclusion Fences (Wellington: Karori Wildlife Sanctuary, 2003).

42 Chris Cochran, Michael Kelly, and Russell Murray, Freshwater Historic Heritage of the Wellington Region: Survey for the Freshwater Plan Review (Wellington: Greater Wellington Regional Council, 2012).

43 Colin Campbell-Hunt and Diane Campbell-Hunt, Eco-Sanctuaries: Communities Building a Future for New Zealand's Threatened Ecologies (Otago, NZ: Printshop Ltd, 2013).

44 Ibid.

\section{BIOGRAPHICAL NOTES}

Bruno Marques is the Programme Director for Landscape Architecture and Senior Lecturer, Victoria University of Wellington, School of Architecture. His main research interests relate to the integration of Indigenous methods in participatory design for landscape rehabilitation and ecosystem services.

Jacqueline McIntosh is a Senior Lecturer at the School of Architecture, Victoria University of Wellington. She is an active researcher, teacher, and supervisor of postgraduate architecture and landscape architecture students. Her current interests are in advancing design and architectural knowledge relating to the use of virtual reality, augmented reality, and related technologies in the design of therapeutic and rehabilitative built environments.

William Hatton: Māori iwi/tribe affiliation: Ngāti Kahungunu ki Wairarapa, Rangitāne and Muaūpoko. Postgraduate student in landscape architecture, Victoria University of Wellington, School of Architecture. His research skills and expertise are related to culture, landscape architecture, and Kaupapa Mãori's subjects.

Danielle Shanahan is a manager of Conservation and Research at the Zealandia sanctuary in Wellington, New Zealand, with a research interest in the connection between people, nature, and well-being.

\section{CONTACT}

\section{Bruno Marques}

Victoria University of Wellington

School of Architecture

PO Box 600

Wellington 6140

New Zealand

Phone: +6444634718

bruno.marques@vuw.ac.nz

Jacqueline McIntosh

Victoria University of Wellington

School of Architecture

PO Box 600

Wellington 6140

New Zealand

Phone: +6444636296

jacqueline.mcintosh@vuw.ac.nz

\section{William Hatton}

Victoria University of Wellington

School of Architecture

PO Box 600

Wellington 6140

New Zealand

Phone: +6444636249

hattonwill@myvuw.ac.nz

Danielle Shanahan

Zealandia Ltd.

PO Box 9267

Te Aro, Wellington 6141

New Zealand

Phone: +64272033288

danielle.shanahan@visitzealandia.com 